\title{
Correction to: Determining ecosystem functioning in Brazilian biomes through foliar carbon and nitrogen concentrations and stable isotope ratios
}

L. A. Martinelli $(\mathbb{D}$ - G. B. Nardoto - A. Soltangheisi - C. R. G. Reis •

A. L. Abdalla-Filho - P. B. Camargo • T. F. Domingues - D. Faria •

A. M. Figueira - T. F. Gomes - S. R. M. Lins - S. F. Mardegan •

E. Mariano - R. C. Miatto - R. Moraes - M. Z. Moreira - R. S. Oliveira •

J. P. H. B. Ometto · F. L. S. Santos · J. Sena-Souza - D. M. L. Silva •

J. C. S. S. Silva $\cdot$ S. A. Vieira

Published online: 30 December 2020

(C) Springer Nature Switzerland AG 2020

Correction to: BiogeochemistryJournal Numbering https://doi.org/10.1007/s10533-020-00714-2

The initial online publication contained typesetting mistakes in the author information. The original article has been corrected.

The original article can be found online at https:// doi.org/10.1007/s10533-020-00714-2.

L. A. Martinelli $(\bowtie) \cdot$ A. Soltangheisi .

A. L. Abdalla-Filho · P. B. Camargo .

T. F. Gomes · E. Mariano · M. Z. Moreira ·

J. C. S. S. Silva

Laboratory of Isotope Ecology, Center for Nuclear Energy

in Agriculture, University of São Paulo, Piracicaba,

SP, Brazil

e-mail: martinelli@cena.usp.br

G. B. Nardoto - C. R. G. Reis - F. L. S. Santos

Ecology Department, Institute of Biological Sciences,

University of Brasília, Brasília, DF, Brazil

T. F. Domingues $\cdot$ R. C. Miatto

Department of Biology, Faculty of Philosophy, Sciences and Letters at Ribeirão Preto, University of São Paulo, Ribeirão Preto, SP, Brazil

D. Faria · R. Moraes

Applied Ecology and Conservation Laboratory, State

University of Santa Cruz, Ilhéus, BA, Brazil
In the original publication, the isotope ratio equation was published with an incorrect value. The correct equation is given here:

$\delta \mathrm{X}(\%)=\left[\left(\frac{R_{\text {sample }}}{R_{\text {standard }}}\right)-1\right] \times 1000$ 
Publisher's Note Springer Nature remains neutral with regard to jurisdictional claims in published maps and institutional affiliations.

J. Sena-Souza

Geoscience Department, State University of Montes

Claros, Montes Claros, MG, Brazil

D. M. L. Silva

Laboratory of Aquatic Biogeochemistry, Department of Biological Sciences, State University of Santa Cruz, Ilhéus, BA, Brasil

S. A. Vieira

Environmental Study and Research Centre, State

University of Campinas, Campinas, SP, Brazil

\section{Springer}

